\title{
ASSESSMENT AND MAPPING OF IRAN DESERTIFICATION INTENSITY USING ARCGIS ENVIRONMENT
}

\author{
H. Khosravi ${ }^{1}$, GH.R. Zehtabian ${ }^{1}$, H. Eskandari Damaneh, ${ }^{1}$ A. Abolhasani ${ }^{1}$ \\ ${ }^{1}$ Department of Reclamation of Arid and Mountains Regions, Faculty of Natural Resources, University of Tehran, Iran- (hakhosravi, \\ ghzehtab, hamed.eskandari)@ut.ac.ir, azamabolhasani67@yahoo.com
}

KEYWORDS: Iran, Desertification, IMDPA, Index, Criterion, Arid Region.

\begin{abstract}
:
Desertification phenomenon is described as one of the most obvious forms of natural resources degradation in the world. This phenomenon, which occurs because of natural factors or anthropogenic factors, is accounted as the third most important global challenge after crisis of water shortage and drought in the $21^{\text {st }}$ century. Awareness of desertification criteria and indicators, investigation of a regional model and determining the most important factors affecting desertification are essential for combating desertification. So in this study, IMDPA model (Iranian Model of Desertification Potential Assessment) was used in order to prepare Atlas of Iran desertification. 8 criteria and 130 indicators affecting desertification have determined for this model. Regarding to these criteria and indicators and quantifying them in arid, semi-arid and dry sub-humid region of Iran, the map of desertification intensity was prepared. The results of this study showed that $88.73 \%$ of the country surface was affected by desertification that is equal to 143365238.6 hectare. The surface more than 49425703.3 hectare equal to $30.59 \%$ of total surface of country was in low desertification class, the surface more than 935677913.6 hectare equal to $57.91 \%$ was in class II or medium and the surface about 371621.7 hectare equal to $0.23 \%$ was in class III or intense. Class IV of desertification or very intense was omitted regarding to IMDPA model and 8 criteria, and natural desert areas which their surface was equal to 15624274.3 hectare or $9.67 \%$ is beyond this class.
\end{abstract}

\section{Introduction}

Desertification means land degradation in arid, semi-arid and dry sub-humid regions because of natural factors or anthropogenic factors. Desertification is accounted as the third most important global challenge after crisis of water shortage and drought in the $21^{\text {st }}$ century (Zehtabian et al, 2010). This phenomenon can reduce soil fertility because of inappropriate utilization, salinization, etc. This is a problem for many countries specially developing countries. Identifying the regions exposed to desertification is so important for combating desertification and leads to better planning (Zehtabian et al, 2013). Many studies have been done in different parts of the world in order to investigate desertification and many models have been presented for preparing desertification maps. The most important of these models are UNEP-FAO, ASSOD, GLASSOD, LADA, and Many studies have been done about application of this model for assessing desertification in different parts of Iran like:

(Zolfaghari and Khosravi, 2016) assessed desertification severity of Saravan using IMDPA model. They have used 4 criteria including climate, vegetation cover, wind erosion and soil in their research. Their results showed that $45.25 \%$ of the region was in medium and $54.39 \%$ of the region was in intensive class of desertification. $0.37 \%$ of the region was residential areas which weren't in any class. Also according to their results climate and soil criteria had the most and the least effect on desertification of Saravan respectively. (Zehtabian et al, 2013) assessed desertification intensity of Garmsar plain using IMDPA model and parameters related to agriculture and groundwater. Their results showed that agricultural factors with geometric mean equal to 2.27 were the most effective factors of Garmsar
MEDALUS. Also in Iran ICD and MICD models have been presented (Bayadgiev, 1981; Basso et al, 1999; Ekhtesasi \& Mohajeri, 1995; European commission, 1999; FAO/UNEP, 2001; Kosmas et al, 1999). It's essential that the criteria and indicators of these models be assessed again and corrected regarding to different areas condition. For this aim, comprehensive plan for quantifying criteria and indicators affecting desertification in natural ecosystems of Iran was prepared in the framework of IMDPA model (Zehtabian et al, 2010; Yektafar et al, 2015). This model have 9 criteria including water, soil, vegetation cover, geomorphology, erosion, agriculture, socio-economic, climate and urban (technology) development which are as desertification criteria and their indicators (130 indicators) are used for quantifying them (Ahmadi, 2004).

desertification. Also their results showed that $83.2 \mathrm{Km}^{2}$ of the whole region was in medium class and $236.8 \mathrm{Km}^{2}$ was in low class of desertification intensity. (Niko, 2011) assessed desertification potential for identifying effective factors on land degradation in Damghan region. (Rafie, 2011) assessed desertification of Yazd-Ardakan plain based on water and climate criteria using IMDPA model. (Kamali et al, 2010) investigated desertification intensity based on water, soil and vegetation cover criteria using IMDPA model in Faryab region. (Vesali, 2008) investigated biophysical indicators of desertification intensity affected by human activities in Kashan and Aran va Bidgol regions using IMDPA model.

Therefore, identifying criteria and indicators affecting desertification and investigation of a regional model is essential for preventing desertification. Regarding to the native nature of 
IMDPA model, it seems that this model should be evaluated in different parts of Iran with different climatic conditions. So the

\section{Methodology}

IMDPA, a comprehensive desertification model, was presented by the faculty of natural resources, university of Tehran, as the result of a project entitled determination methodology of desertification criteria and indices in arid and semiarid regions of Iran. IMDPA is a proper model for assessing desertification intensity in different parts of Iran. This model presents acceptable results because of using geometric mean for estimating criteria and indexes affecting desertification. Regarding to this issue, this model was used in order to prepare Atlas of Iran desertification. For this aim, 8 criteria were selected as desertification criteria and their indexes were used for quantifying them. At first, 130 indicators were selected for all 9 criteria, but preparing information of all of them for the whole of the country was impossible, costly and also time consuming. So for each criterion, up to 4 key indicators were identified. Criteria and indexes are as follow:

- Climate: drought, aridity index, rainfall amount.

- Geomorphology: land use, rock sensitivity and physiography.

- Soil: EC, texture, depth, gravel percentage.

Index $\left.-X=[(\text { Layer }-1) .(\text { layer }-2) . .(\text { Layer }-n)]^{1 / n}\right)$

Index X: each criterion

Layer: indicators related to each criterion

$\mathrm{N}$ : number of indicators related to each criterion

For example, numerical value of water criterion is obtained according to the following formula:

$$
\mathrm{Q} 3=\sqrt[4]{Q 3.1 * Q 3.2 * Q 3.3 * Q 3.4}
$$

Weighted averages of indicators related to each criterion were determined and finally desertification intensity was gain based on geometric mean of all criteria according to the formula below: aim of this study was assessing desertification intensity in Iran using IMDPA model.

- Vegetation cover: coverage status, coverage utilization and vegetation cover rehabilitation

- Water: negative balance of water, groundwater depletion, EC and SAR.

- Erosion: water erosion (vegetation cover density, land use and water erosion density and type) and wind erosion (days with dust storm index, vegetation cover, non-living cover density and erosion facies appearance).

- Socio-economic: socio-cultural factors, organization and participation, awareness, experience and native knowledge.

- Agriculture: cultivation patterns, crop performance and application of inputs and machinery.

- Urban or technology development: mine and road density, converting forests and rangelands to urban and industrial areas, improper agriculture, converting garden lands to residential-industrial regions and amount of green space per person.

In this study, each index received a weight (1 to 4) according to the expert opinion and each criterion was obtained based on its indicators geometric mean according to the formula below:

Desertification intensity $=\Sigma \sqrt[1 / 9]{\text { water } \times \text { soil } \times \text { vegetation } \ldots . . \times \text { socio }- \text { econ }}$

Final map of desertification intensity was determined using different layers and obtained maps related to each criterion and combination of layers and maps. So, map of each criterion was obtained from its own indicators. These maps can be used for the study of each index quality and its effect on desertification. Table (1) shows intensity classification of desertification status.

\begin{tabular}{|c|c|c|}
\hline order & Numerical value & class \\
\hline 1 & $1-1.5$ & Low \\
\hline 2 & $1.6-2.5$ & Medium \\
\hline 3 & $2.6-3.5$ & High \\
\hline 4 & $3.6-4$ & Very high \\
\hline
\end{tabular}

Table 1 . Intensity classification of desertification status 


\section{Result}

The result of classification of desertification intensity is shown in table 2 :

\begin{tabular}{|c|c|c|c|}
\hline row & Desertification classes & Are (ha) & $\begin{array}{c}\text { \% (relative to the total area } \\
\text { of country) }\end{array}$ \\
\hline 1 & Low (I) & 494257033 & 30.59 \\
\hline 2 & Medium (II) & 93567913.6 & 57.91 \\
\hline 3 & Intensive (III) & 371621.8 & 0.023 \\
\hline 4 & Very intensive (IV) & - & 0.0 \\
\hline 5 & Total area affected by desertification & 143365238.6 & 88.73 \\
\hline 6 & Natural deserts & 15624274.3 & 9.67 \\
\hline 7 & Affectless areas & 2585195.3 & 1.60 \\
\hline 8 & Total area & 161574708.3 & 100 \\
\hline
\end{tabular}

Table 1. Classification of desertification intensity

Map of desertification potential zoning is shown in figure 1:

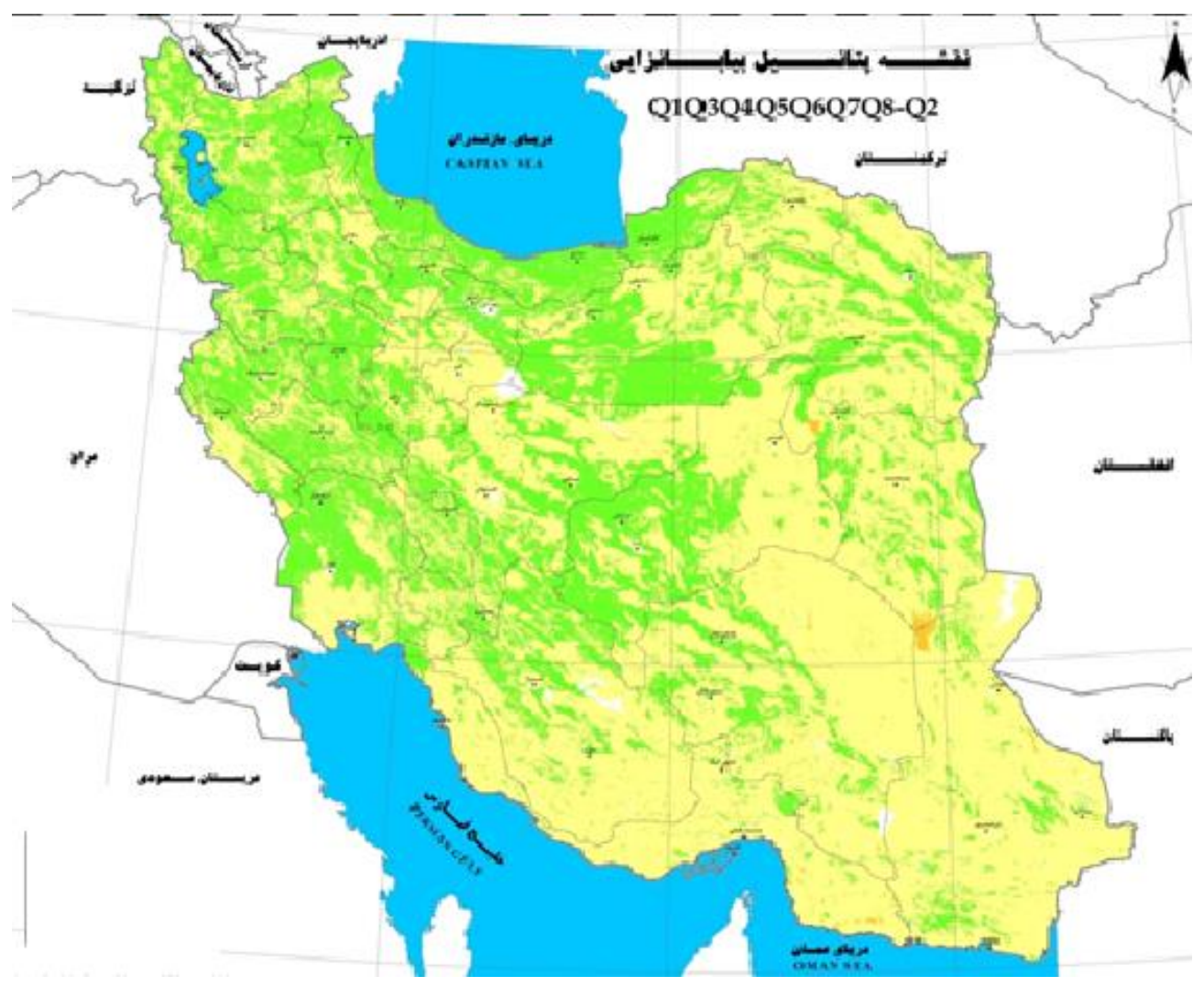

\section{Legend}

Q1Q2Q3Q4Q5Q6Q7Q8

Class

Low

Medium

Intensive

very Intensive

Figure 1. zoning of desertification status in Iran

\subsection{Map of water and irrigation criterion}


One of the important criteria for determining desertification intensity is water and irrigation criterion. The result of quantitative value of this criterion that was determined using its indicators is shown in figure (2). Zoning map of Iran plains based on Q3 is shown in figure (3).

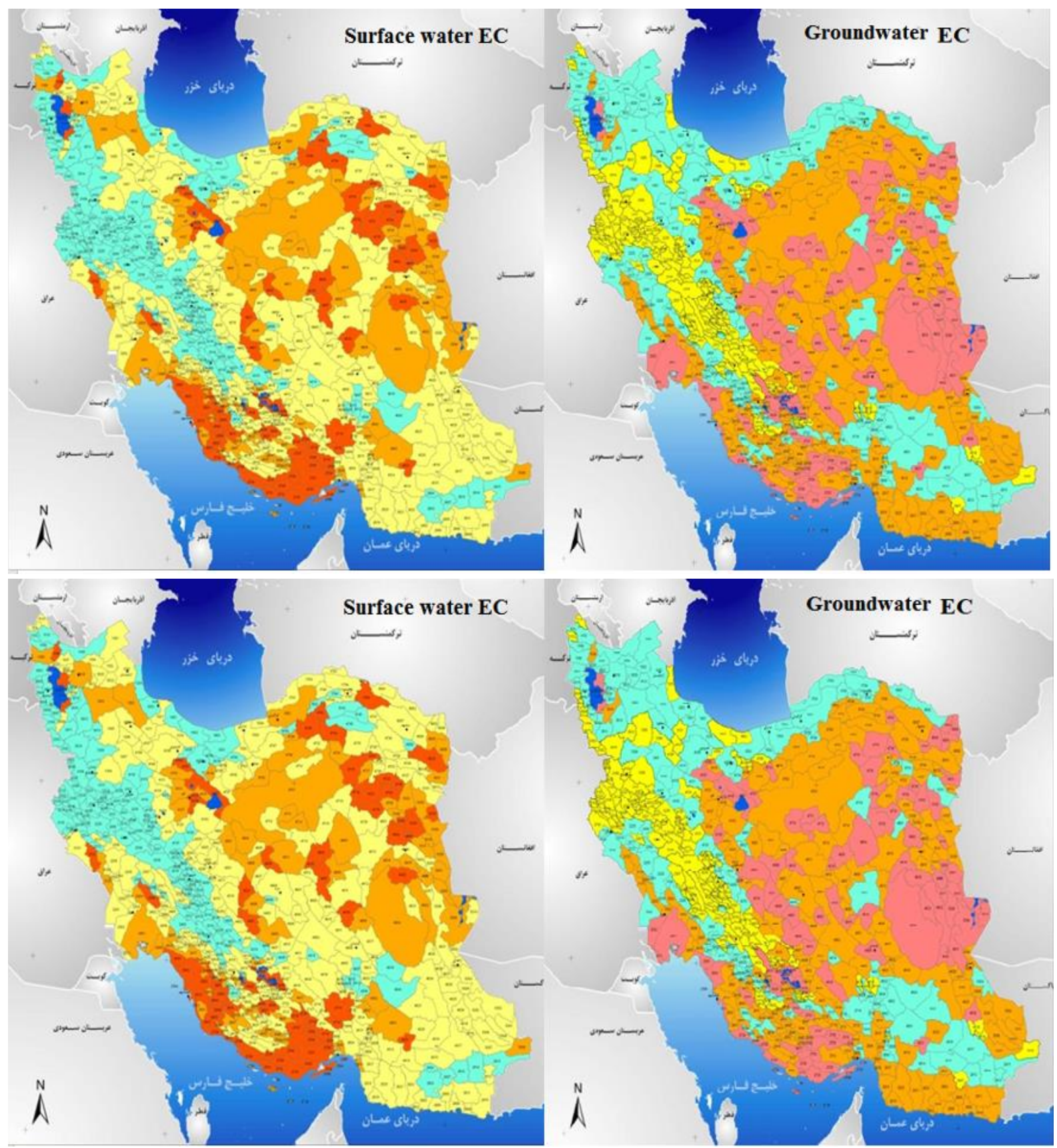

\section{Legend}

Class Index Weight

$\begin{array}{ll}\text { Low } & \mathbf{0 . 0 5 - 1} \\ \text { Medium } & \mathbf{1 . 1 - 2} \\ \text { Intensive } & \mathbf{2 . 1 - 3} \\ \text { very Intensive } & \mathbf{3 . 1 - 4}\end{array}$

Figure 2. The map of water and irrigation criterion 


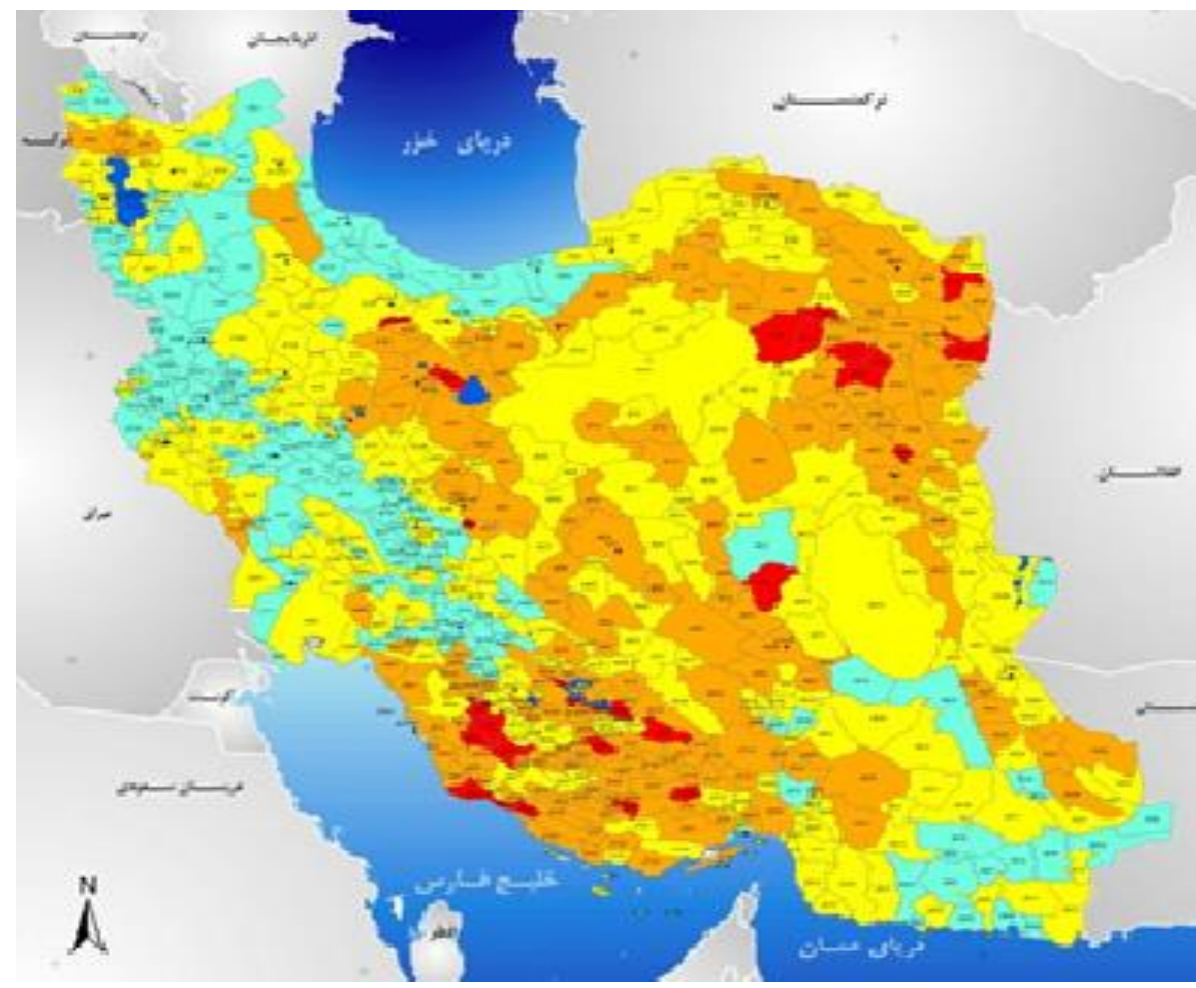

Legend

$\begin{array}{lr}\text { Class Index Weight } \\ \text { Low } & \mathbf{0 . 0 5}-1 \\ \text { Medium } & 1.1-2 \\ \text { Intensive } & \mathbf{2 . 1 - 3} \\ \text { very Intensive } & \mathbf{3 . 1 - 4}\end{array}$

Figure 3. zoning of the country based on water and irrigation criterion

The results of these calculations are shown in table 3:

\begin{tabular}{|c|c|c|c|c|}
\hline Row & $\begin{array}{c}\text { Classiffication of desertification } \\
\text { intensity }\end{array}$ & classes & Area (ha) & $\begin{array}{c}\text { (relative to total } \\
\text { area of Iran) }\end{array}$ \\
\hline 1 & Affectless & O & 3347827.9 & 2.072 \\
\hline 2 & Low & I & 56777352.5 & 35.14 \\
\hline 3 & Medium & II & 58344627.2 & 36.110 \\
\hline 4 & Intensive & 24478568.3 & 15.15 \\
\hline 5 & Very intensive & 433020.3 & 0.268 \\
\hline 6 & IV & 143381396.2 & 88.74 \\
\hline 7 & Areas affected by water and & - & 2585195.3 & 1.60 \\
\hline 8 & \multicolumn{2}{|c|}{ Affectless areas } & 156081116.8 & 9.66 \\
\hline 9 & \multicolumn{2}{|c|}{ Natural deserts } & 18193312.1 & 11.26 \\
\hline 10 & Total areas with no effect on desertification & 161574708.3 & 100 \\
\hline
\end{tabular}

\section{Conclusion}

In this research IMDPA model was used in order to prepare Atlas of Iran desertification. This model has 8 criteria which are as desertification criteria and their indicators are used for quantifying them. At first 130 indicators were selected for all 9 criteria but in one hand it wasn't possible to prepare information of all of them for the whole of country and on the other hand it was costly and time consuming. So for each criterion, up to 4 key indicators were identified. Desertification intensity map of Iran was determined using these criteria and indices and also quantifying them in arid, semi-arid and sub humid regions. The results showed that $88.73 \%$ of the country surface was affected by desertification that is equal to 143365238.6 hectare. The surface more than 49425703.3 hectare equal to $30.59 \%$ of total surface of country was in low desertification class, the surface more than 935677913.6 hectare equal to $57.91 \%$ was in class II or medium and a surface about 371621.7 hectare equal to $0.23 \%$ was in class III or intense. Class IV of desertification or very intense was omitted regarding to IMDPA model and 8 criteria, and natural desert areas which their surface was equal to 15624274.3 hectare or $9.67 \%$ is beyond this class. 


\section{REFERENCES}

Basso, F., Belloti, A., Faretta, S., Ferara, A., Manino, G., Pisante, M., Quaranta, G., Tabemer, M., 1999. The Agri Basin In: MEDALUS Project-Mediterranean Desertification and Land Use.Manual on Key indicators of desertification and mapping Environmentally Sensitive areas to desertification.

Bayadgiev, T., 1981. FAO/UNEP Project of Desertification Assessment and Mapping.

Ekhtesasi, M.R., Mohajeri, S., 1995. Iranian Classification of Desertification model (ICD), the second national conference of desert areas problems of Iran.

European Commission., 1999. Mediterranean Desertification and Land Use. (MEDALUS). MEDALUS Office, Landan.

FAO/UNEP, Land Degradation Assessment in Dryland (LAND), 2001. United Nations Environment Program, Global Environment Facility, PP 67.

Kamali, M., 2010. assessing and preparing desertification intensity map based on IMDPA model with emphasize on water, soil and vegetation criteria (Case study: Faryab basin), thesis for Master degree, faculty of natural resources, university of Tehran.

Kosmas, C., Kirkby, M., Geeson, N., 1999. European Commission the MEDALUS Project Mediterranean Desertification and Land Use.

Niko, sh., 2011. assessing desertification potential based on IMDPA model in order to determine effective factors on land degradation (Case study: Damghan region), thesis for PHD degree, faculty of natural resources, university of Tehran.

Rafie, J., 2011. assessing and monitoring desertification using IMDPA model with emphasize on water and climate criteria (Case study: Yazd-Ardakan plain), thesis for Master degree, faculty of natural resources, university of Tehran.

Vesali, 2008. investigation of biophysical indicators of desertification intensity affected by human activities using IMDPA model (Case study: Kashan and Aran va Bidgol regions), thesis for Master degree, faculty of natural resources, university of Tehran.

Yektafar, M., Zare, M., Akhavan Ghalibaf, M., Mahdavi Ardakani, S.R., 2016. Comparison of Desertification Intensity in the Purified Wastewater Irrigated Lands with Normal Lands in Yazd Using of Soil Criterion of the IMDPA Model, Journal of Water and Soil, 29(6), 1506-1521.

Zehtabian, G.R., Esfandiari, M., 2011. Evaluation of the agricultural development and groundwater use on desertification in Tashk region, Fars province, Arid Biom Scientific and Research Journal, 1(2).

Zehtabian, Gh.R., Azareh, A., NazariSamani, A., Khosravi, H., 2013. Effect of Water and Agriculture Criteria on Desertification (Case study: Garmsar plain), International Journal of Agronomy and Plant Production, 4(7), 1721-1730.

Zolfaghari, F., Khosravi, H., 2016. Assessment of desertification intensity of Saravan region using IMDPA model, Journal of Geography and Environmental Planning (GEP), 27(2), 87-102. 